\title{
OVIPOSITION DETERRENT AND OVICIDAL ACTIVITY OF THREE EDIBLE OILS (BLACK SEED, SESAME AND SOYBEAN OILS) AGAINST PULSE BEETLE, CALLOSOBRUCHUS CHINENSIS (LIN.) (COLEOPTERA: BRUCHIDAE) ON GREEN GRAM, VIGNA RADIATA
}

\author{
Sharmin Akter, Shanjida Sultana, Tangin Akter and Shefali Begum* \\ Department of Zoology, University of Dhaka, Dhaka-1000, Bangladesh
}

\begin{abstract}
The effectiveness of three different edible oils - black seed (Nigella sativa), sesame (Sesamum indicum) and soybean (Glycene max) was evaluated for the control of pulse beetle, Callosobruchus chinensis on green mung pulse, Vigna radiata. The oviposition deterrent and ovicidal activity of these three oils were compared between fresh mung pulses and pulses treated at different doses $(1,3$ and $6 \mu \mathrm{l}$ ). The results indicated that the rate of oviposition and the mean number of emerged adults of $C$. chinensis on mung pulses treated with black seed, sesame and soybean oil were lower than their respective control pulses. The lowest number of eggs were recorded in soybean oil treated seeds $(13.8 \pm 1.07,12.6 \pm$ $1.36,10.0 \pm 1.82)$ followed by sesame $(51.8 \pm 4.63,25.8 \pm 8.52,14.2 \pm 4.50)$ and black seed oil $(67.2 \pm 9.71,27.4 \pm 5.52,21.0 \pm 5.54)$ at dose $1 \mu \mathrm{l}, 3 \mu \mathrm{l}$ and $6 \mu \mathrm{l}$, respectively in order. Soybean oil at the rate of 6ul/50 seeds was significantly effective $(10.0 \pm 1.82)$ to inhibit egg deposition. In case of ovicidal activity, minimum number of adults were emerged from black seed oil treated pulses (25.2 $\pm 2.73,24.2 \pm 0.58,22.4 \pm 1.17$ at dose 1,3 and $6 \mu l$, respectively). Black seed oil at the rate of $6 \mu \mathrm{l} / 50$ seeds was the most effective $(22.4 \pm 1.17)$ than other edible oils.
\end{abstract}

Key words: Oviposition, deterrent, ovicidal activity, pulse beetle, edible oil.

\section{INTRODUCTION}

Pulses are very important item of human food in daily diet and are rich source of vegetable protein, mineral and vitamin-B. In developing countries, pulse nutrition are great alternatives of animal protein for the underprivileged people (Aslam et al. 2002). Besides providing human nutrition, pulses are also important for sustainable agriculture. Pulses have unique property of maintaining and restoring soil fertility and their falling leaves improve the physical properties of soil (Chakrabarty et al. 2015). In Bangladesh, mung pulses are annual and seasonal crop which can be stored for several months. The initial infestation starts in the field, but the pest population increases rapidly in storage condition. In tropical and subtropical countries, insect pests attack pulse seeds during storage and cause a great damage. Among the important insect pests of stored grain, the pulse beetle, Callosobruchus chinensis

*Author for correspondence: <shefali@du.ac.bd>

(C) 2018 Zoological Society of Bangladesh DOI: https://doi.org/10.3329/bjz.v47i1.42021 
(Lin.) (Coleoptera: Bruchidae) is the most widespread and destructive pest of stored grains (Park et al. 2003). It is considered as a serious pest of green gram, chickpea, black gram, peas, cowpea, lentil and pigeon pea. These insects have been reported from Japan, Philippines, Indonesia and the Indian sub-continent (Aslam et al. 2002). The beetles cause great damage to pulse seeds both qualitatively and quantitatively which results in weight loss, decreased germination potential and reduction in commercial value of the seed (Okunola 2003). Gujar and Yadav (1978) reported 55 - 60\% weight loss of stored pulse and 46 - 66\% loss in protein content by infestation with the beetles.

A large number of studies have been carried out on the efficacy of different kinds of vegetable oils against Callosobruchus spp. The use of vegetable oils has been known to protect seeds from bruchids infestation in many pulse crops (Khalequzzaman et al. 2007). It has been reported that oviposition and seed damage rate were reduced and adult emergence of bruchids was suppressed when powder or oil extracts of plants were mixed with some stored grains (Shaaya et al. 1997). It has been observed that plant oils such as mustard, soybean, coconut, sesame, linseed, palm, joytoon, olive, neem and castor oil at the rate of 5 and $10 \mathrm{ml} / \mathrm{kg}$ of seeds were applied to control the infestation of mungbeans by pulse beetle, $C$. chinensis in storage condition. Results showed that there was a significant reduction in oviposition and the adult emergence was also completely inhibited on the seeds treated with mustard, coconut, soybean and neem oils at the rate of $10 \mathrm{ml} / \mathrm{kg}$ of seeds. The experiment indicated that the higher doses of oils gave the better control (Rahman and Rahman 2004). Choudhury and Pathak (1989) reported that different oils as neem, groundnut, soybean and sesame were highly effective against the pests attacking stored products even at a low concentration of $0.25 \mathrm{ml} / 100 \mathrm{~g}$ seed. Chemical insecticides are mainly applied for successful storage but these chemicals are hazardous to human health and cause environmental pollution. For this reason, there is a continuous need to protect the stored products from massive damage, especially from loss of quality and weight during storage. Therefore, there is a need to evaluate various botanicals to identify the ones which are not only effective but also health wise acceptable. The present experiment was done to study the oviposition deterrent and ovicidal activity of different edible oils against $C$. chinensis (Coleoptera: Bruchidae) on green mung bean, $V$. radiata.

\section{MATERIAL AND METHODS}

Experiment on the effectiveness of various doses of three different edible oils against the infestation of the pulse beetle, C. chinensis L. on mung pulse was 
conducted in the Entomology laboratory, Department of Zoology, University of Dhaka. The oils used in the experiment were black seed (Nigella sativa), sesame (Sesamum indicum) and soybean (Glycine max) oil. The doses of oils were 1, 3 and $6 \mu \mathrm{l} / 50$ seeds. All experiments were done at $30^{\circ} \mathrm{C}$ and $70 \%$ relative humidity within an incubator. The green mung pulses were collected from Kawran bazar, Dhaka, these were washed thoroughly with water to remove dust, insect infesting materials and any trace of other pesticide from surface of the seeds. Then the seeds were dried under sunlight for one day carefully and kept in a closed air tight container. The pulse beetles were collected from Kawran Bazar from where the pulses were collected and were brought to the laboratory. These were carefully identified and confirmed as Callosobruchus chinensis (Lin.) according to Southgate's description (1957 and 1958).

For stock culture of the pulse beetle, $C$. chinensis, mung pulse was selected as rearing medium. These were maintained in five large Petri dishes (10" diameter) within incubator at temperature $30^{\circ} \mathrm{C}$ and $70 \%$ relative humidity (RH). Each Petri dish was filled with approximately equal quantities (50 g) of mung pulse seeds. Fifty pairs of adult pulse beetles were released into each of five Petri dishes for oviposition. The Petri dishes were marked with date and the pulse beetles were allowed to oviposit on the mung seeds for about $24 \mathrm{hrs}$ to obtain sufficient numbers. After 24 hours, the adults were removed and thus a continuous series of stock cultures were maintained in the laboratory.

To study the oviposition deterrent activity, the doses as 1,3 and $6 \mu$ of black seed, sesame and soybean oil were taken by micropipette and mixed thoroughly with 50 fresh mung seeds by a plastic needle and marked as treated seeds. Then 50 control seeds and 50 treated seeds were taken in a Petri dish for choice test. The Petri dish was marked as $\mathrm{C}$ - for control seeds and T- for treated seeds. Five pairs of adult $C$. chinensis from the stock culture were introduced carefully into the Petri dish after the next day of emergence. The beetles were allowed to lay eggs freely for 24 hours. Then the adults were removed from the Petri dishes. Eggs laid on both control and treated seeds were counted by using magnifying glass.

To observe the ovicidal activity, 50 pairs of adult $C$. chinensis (male and female) were introduced into two Petri dishes (10") containing $50 \mathrm{~g}$ fresh mung seeds. The adults were allowed there for $24 \mathrm{hrs}$ to lay eggs freely. Then the adults were removed from the Petri dish and the egg bearing seeds (each seed with one egg) were separated. After that two pairs of Petri dishes were taken and 50 egg bearing seeds were introduced into each pair of Petri dishes. The Petri dishes were marked as $\mathrm{C}$ and $\mathrm{T}$. Then oils (black seed, sesame and soybean oil) were mixed carefully with the seeds of treated Petri dish. The doses of oils were 
1, 3 and $6 \mu \mathrm{l}$ and measured by a micropipette. The Petri dishes were kept within the incubator until adult emergence. After the emergence of adults, the insects were taken out from the Petri dishes and were counted.

Data were analyzed statistically by calculating mean, standard error and t test.

\section{RESULTS AND DISCUSSION}

The present study was conducted to prevent the damage of mung pulse caused by pulse beetle, $C$. chinensis (Lin.). The oviposition deterrent and ovicidal activity of three edible oils (black seed, sesame and soybean) at different doses (1, 3 and $6 \mu \mathrm{l}$ ) against pulse beetle, $C$. chinensis (Lin.) on green mung pulse was evaluated.

Effect on egg laying in a choice test: The rate of oviposition was significantly lower in treated seeds than their respective controls. The effectiveness of oils increased with the increase of doses (Table 1). Among three edible oils (black seed, sesame and soybean), the lowest number of eggs (10.0 \pm 1.82$)$ were laid on pulses treated with $6 \mu \mathrm{l}$ of soybean oil (Table 1). Bhardwaj and Verma (2012) used six vegetable oils (mustard, neem, karanj, cedar, apricot and olive) for protection of pea seed from pulse beetle, C. chinensis. Maximum mortality $(22.22 \%)$ was observed in neem oil coated seeds. Complete mortality was observed in seeds coated with neem oil at 5 per cent concentration. The minimum number of eggs and adult emergence were recorded in neem oil coated seeds. Singh (2003) also reported that different edible and non-edible oil act as surface protectants against $C$. chinensis at $8 \mathrm{ml} / \mathrm{kg}$ seed for pigeon pea seeds. All oils proved highly effective in preventing oviposition and controlling the adult emergence of the beetle.

Table 1. The comparison of oviposition deterrent activity of three edible oils (black seed, sesame and soybean oil) at different doses (1, 3 and $6 \mu 1 / 50$ seeds, respectively) along with their respective controls

\begin{tabular}{|c|c|c|c|c|c|c|}
\hline \multirow{3}{*}{$\begin{array}{l}\text { Edible } \\
\text { oils }\end{array}$} & \multicolumn{6}{|c|}{ No. of egg laid/doses } \\
\hline & \multicolumn{2}{|c|}{$1 \mu \mathrm{l}$} & \multicolumn{2}{|c|}{$3 \mu \mathrm{l}$} & \multicolumn{2}{|c|}{$6 \mu \mathrm{l}$} \\
\hline & Control & Treatment & Control & Treatment & Control & Treatment \\
\hline Black seed & $86.8 \pm 7.79$ & $67.2 \pm 9.71$ & $55.4 \pm 4.08$ & $27.4 \pm 5.52$ & $42.4 \pm 4.50$ & $21.0 \pm 5.54$ \\
\hline Sesame & $94.4 \pm 2.87$ & $51.8 \pm 4.63$ & $38.0 \pm 6.63$ & $25.8 \pm 8.52$ & $46.6 \pm 2.78$ & $14.2 \pm 4.50$ \\
\hline Soybean & $123.0 \pm 2.33$ & $13.8 \pm 1.07$ & $54.4 \pm 2.14$ & $12.6 \pm 1.36$ & $63.2 \pm 7.64$ & $10.0 \pm 1.82$ \\
\hline
\end{tabular}

*Significant at $\mathrm{p}=0.05$.

The three edible oils significantly varied in oviposition deterrent activity at different doses $(1,3$ and $6 \mu \mathrm{l})$ at $\mathrm{p}=0.05$. The oviposition deterrent activity at 
the dosage of $1 \mu \mathrm{l}$ did not significantly vary between black seed oil and sesame oil ( $p>0.05$ ); however it varied significantly between black seed oil and soybean oil and also between sesame oil and soybean oil $(\mathrm{p}<0.05)$. When the pulses were treated with 3 and $6 \mu \mathrm{l}$ of three edible oils (black seed, sesame and soybean), the oviposition deterrent activity did not vary between black seed oil and sesame oil and also between sesame oil and soybean oil ( $p>0.05$ ); but it significantly varied between black seed oil and soybean oil $(p<0.05)$ (Table 2$)$.

Table 2. The comparison of oviposition deterrent activity of three edible oils (black seed, sesame and soybean oil) at different doses (1, 3 and $6 \mu 1 / 50$ seeds, respectively)

\begin{tabular}{llcl}
\hline \multirow{2}{*}{$\begin{array}{l}\text { Edible } \\
\text { oils }\end{array}$} & \multicolumn{3}{c}{ No. of egg laid/doses } \\
& Mean $\pm \mathrm{SE}$ & Mean $\pm \mathrm{SE}$ & Mean $\pm \mathrm{SE}$ \\
\hline Black seed & $67.2 \pm 9.71 \mathrm{ab}$ & $27.4 \pm 5.52 \mathrm{ab}$ & $21.0 \pm 5.54 \mathrm{ab}$ \\
Sesame & $51.8 \pm 4.63 \mathrm{~b}$ & $25.8 \pm 8.52 \mathrm{bc}$ & $14.2 \pm 4.50 \mathrm{bc}$ \\
Soybean & $13.8 \pm 1.07 \mathrm{c}$ & $12.6 \pm 1.36 \mathrm{c}$ & $10.0 \pm 1.82 \mathrm{c}$ \\
\hline
\end{tabular}

Mean followed by different letters varied significantly at $\mathrm{p}=0.05$.

Effect on adult emergence: The mean number of adults emerged from control and treated seeds were significantly different. The rate of adult emergence was significantly lower from treated seeds than their respective controls. The lowest number of adults $(22.4 \pm 1.17)$ were emerged from seeds treated with $6 \mu$ dose of black seed oil. The rate of adult emergence was decreased with the increase of doses of oils which means the ovicidal activity of the three edible oils increased with the increase of doses of oils (Table 3). Similar findings were reported by Chaubey (2008) who reported that the essential oil of Nigella sativa was most effective against all the different stages of the $C$. chinensis. The essential oils of $N$. sativa caused death of adults and larvae of $C$. chinensis and significantly inhibited the emergence of adults of $C$. chinensis when fumigated with sublethal concentrations. Tawfeek et al. (2017) tested fennel oil, caraway oil, cinnamon oil, citronella oil, nutmeg oil and black cumin oil against three stored products. The result indicated that with the increase of the oil concentration and exposure times, percentage of adult mortality increased significantly.

The ovicidal activity of three edible oils vary significantly at different doses $(1,3$ and $6 \mu \mathrm{l})$ at $\mathrm{p}=0.05$. The ovicidal activity at the dose of $1 \mu \mathrm{ll}$ varied significantly between black seed and sesame oil; and black seed and sesame oil $(\mathrm{p}<0.05)$ but did not vary significantly between sesame and soybean oil ( $\mathrm{p}>$ 0.05). At the dose of $3 \mu \mathrm{l}$, the ovicidal activity significantly varied between black seed and sesame oil; and sesame and soybean oil $(p<0.05)$ but did not vary 
between black seed and soybean oil ( $\mathrm{p}>0.05$ ). But at the dose of $6 \mu \mathrm{l}$, the ovicidal activity did not vary between black seed, sesame and soybean oil ( $\mathrm{p}>$ 0.05) (Table 4).

Table 3. The comparison of ovicidal activity of three edible oils (black seed, sesame and soybean oil) at different doses (1, 3 and $6 \mu$ l/50 seeds, respectively) along with their respective controls

\begin{tabular}{|c|c|c|c|c|c|c|}
\hline \multirow{3}{*}{$\begin{array}{l}\text { Edible } \\
\text { oils }\end{array}$} & \multicolumn{6}{|c|}{ No. of adults/doses } \\
\hline & \multicolumn{2}{|c|}{$1 \mu \mathrm{l}$} & \multicolumn{2}{|c|}{$3 \mu \mathrm{l}$} & \multicolumn{2}{|c|}{$6 \mu \mathrm{l}$} \\
\hline & Control & Treatment & Control & Treatment & Control & Treatment \\
\hline Black seed & $29.8 \pm 3.15$ & $25.2 \pm 2.73$ & $39.2 \pm 2.03$ & $24.2 \pm 0.58^{*}$ & $33.0 \pm 0.84$ & $22.4 \pm 1.17^{*}$ \\
\hline Sesame & $26.4 \pm 7.46$ & $36.2 \pm 2.80$ & $35.6 \pm 2.69$ & $33.8 \pm 1.98$ & $35.2 \pm 2.73$ & $26.4 \pm 2.34^{*}$ \\
\hline Soybean & $35.4 \pm 2.16$ & $33.8 \pm 1.74$ & $31.0 \pm 6.39$ & $25.4 \pm 0.75$ & $30.2 \pm 1.43$ & $23.6 \pm 1.25^{*}$ \\
\hline
\end{tabular}

*Significant at $\mathrm{p}=0.05$.

Table 4. Ovicidal activity of three edible oils (black seed, sesame, soybean oil) at different doses (1, 3 and $6 \mu 1 / 50$ seeds, respectively)

\begin{tabular}{lccc}
\hline & \multicolumn{3}{c}{ No. of adults/doses } \\
\cline { 2 - 4 } Edible oils & $1 \mu \mathrm{l}$ & $3 \mu \mathrm{l}$ & $6 \mu \mathrm{l}$ \\
\cline { 2 - 4 } & Mean $\pm \mathrm{SE}$ & Mean $\pm \mathrm{SE}$ & Mean $\pm \mathrm{SE}$ \\
\hline Black seed & $25.2 \pm 2.73 \mathrm{a}$ & $24.2 \pm 0.58 \mathrm{a}$ & $22.4 \pm 1.17 \mathrm{ab}$ \\
Sesame & $36.2 \pm 2.80 \mathrm{~b}$ & $33.8 \pm 1.98 \mathrm{~b}$ & $35.2 \pm 2.34 \mathrm{bc}$ \\
Soybean & $33.8 \pm 1.74 \mathrm{bc}$ & $25.4 \pm 0.75 \mathrm{ca}$ & $23.6 \pm 1.25 \mathrm{ca}$ \\
\hline
\end{tabular}

Mean followed by different letters varied significantly at $\mathrm{p}=0.05$.

It can be presumed that the three edible oils were effective in reducing egg deposition and adult emergence. Results showed that soybean oil was the best to decrease the rate of oviposition and black seed oil was the best in controlling the rate of adult emergence. So, in this manner, black seed, sesame and soybean oils can be utilized as environmentally safe management technique to control C. chinensis in protecting pulse seeds.

\section{LITERATURE CITED}

ASLAM, M., KHAN, K.A. and BAJWA, M.J.H. 2002. Potency of some spices against C. chinensis (Lin.) J. Biol. Sci. 2(7): 449-452.

BHARDWAJ, A. and VERMA, S.C. 2012. Evaluation of vegetable oils against pulse beetle, Callosobruchus chinensis (Coleoptera: Bruchidae) infesting pea seeds (Pisum sativum 1.). Pest Manag. Hort. Ecosyst. 18(1): 46-53.

CHAKRABORTY, S., MONDOL, P. and SENAPATI, S.K. 2015. Evaluation of relative susceptibility of Callosobruchus chinensis (Lin.) on five different stored pulse seeds. Asian J. Plant Sci. Res. 5(10): 9-15. 
CHAUBEY, M.K. 2008. Fumigant toxicity of essential oils from some common spices against pulse beetle, Callosobruchus chinensis (Coleoptera: Bruchidae). J. Oleo. Sci. 57(3): 171-179.

CHOUDHURY, B.S. and PATHAK, S.C. 1989. Efficacy of organic materials for the control of Callosobruchus chinensis (Lin.) Indian J. Plant Prot. 17: 47-51.

GUJAR, G.T. and YADAV, T.D. 1978. Feeding of Callosobruchus maculatus F. (Coleoptera: Bruchidae) reared on different foods and temperature. J. Stored Prod. Res. 22: 71-75.

KHALEGUZZAMAN, M., MAHDI, S.H.A. and GONI, S.H.M.O. 2007. Efficacy of edible oils in the control of pulse beetle, Callosobruchus chinensis (Lin.) in stored pigeonpea. Univ. J. Zool. Rajshahi Univ. 26: 89-92.

OKUNOLA, C.O. 2003. Use of melon oil for the control of bruchid damage in cowpea. In: Proceedings of African Crop Science Society, Ondo State, Nigeria 6: 238-240.

PARK, I., LEE, S., CHOI, D., PARK, J. and AHM, Y. 2003. Insecticidal activities of constituents identified in the essential oil from the leaves of Chamaecyparis obtuse against C. chinensis (Lin.) and S. oryzae (Lin.). J. Stored Prod. Res. 39: 375-384.

RAHMAN, M.H. and RAHMAN, H. 2004. Efficacy of different plant oils for the control of pulse beetle, C. chinensis infestation of mungbeans in storage condition. Bangladesh J. Zool. 32(2): 181-186.

SHAAYA, E., KOSTJUKOVSKI, M., EILBERG, J. and SUKPRAKANN, C. 1997. Plant oils as fumigants and contact insecticides for the control of stored-product insects. J. Stored Prod. Res. 33(1): 7-15.

SINGH, P.K. 2003. Effect of some oils against pulse beetle, Callosobruchus chinensis in infesting pigeon pea. Indian J. Entomol. 65: 55-58.

SOUTHGATE, B.J. 1957. The specific status of Callosobruchus maculatus F. and C. analis F. Bull. Ent. Res. 48(1): 29-89.

SOUTHGATE, B.J. 1958. Systemic notes on species of Callosobruchus of economic importance. Bull. Ent. Res. 49(3): 591-599.

TAWFEEK, M.E., ABU-SHALl, A.M.H., GAD, A.A. and MOHEY, M. 2017. Evaluation of six plant essential oils against three stored product insects and their effects on the Haemogram under laboratory conditions. Alex. J. Agric. Sci. 62(3): 291-301

(Manuscript received on 27 November, 2018; revised on 10 Apri, 2019) 